\title{
Heparin Sodium
}

National Cancer Institute

\section{Source}

National Cancer Institute. Heparin Sodium. NCI Thesaurus. Code C833.

The sodium salt form of heparin. As a glycosaminoglycan anticoagulant, heparin sodium binds to antithrombin III to form a heparin-antithrombin III complex. The complex binds to and irreversibly inactivates thrombin and other activated clotting factors $\mathrm{IX}, \mathrm{X}, \mathrm{XI}$, and $\mathrm{XII}$ and prevents the transformation of fibrinogen to fibrin. $(\mathrm{NCl})$ 